\title{
Effects of intravenous dexmedetomidine on $0.5 \%$ hyperbaric bupivacaine spinal anesthesia - a placebo controlled randomized trial
}

\author{
Ruma Thakuria $^{1}$, Tridip Jyoti Borah ${ }^{2, *}$, Jaideep Sonowal ${ }^{3}$, Dipika Choudhury ${ }^{4}$
}

\begin{abstract}
${ }^{1}$ Senior Resident, Dept. of Anesthesiology, All India Institute of Medical Sciences, New Delhi, ${ }^{\mathbf{2}}$ Assistant Professor, ${ }^{\mathbf{3}}$ Senior Resident, Dept. of Anesthesiology, North Eastern Indira Gandhi Regional Institute of Health and Medical Sciences, Shillong, Meghalaya, ${ }^{4}$ Professor and HOD, Dept. of Anesthesiology, Gauhati Medical College and Hospital, Guwahati, Assam, India
\end{abstract}

\author{
*Corresponding Author: \\ Email: tridipborah2@rediffmail.com
}

Received: $19^{\text {th }}$ November, 2017

Accepted: $1^{\text {st }}$, June, 2018

\begin{abstract}
Introduction and Aim: Dexmedetomidine, a neuraxial adjuvant, when given intrathecally with hyperbaric bupivacaine provides stable hemodynamic conditions, good quality of intraoperative and prolonged postoperative analgesia with minimal side effects. When intravenous dexmedetomidine is used in conjunction with neuraxial anesthesia, few studies have shown that it prolongs the sensory-motor blockade and provides better intraoperative and postoperative analgesia. We formulated this hypothesis that intravenous (IV) dexmedetomidine bolus followed by infusion would prolong the duration of subarachnoid block (SAB) with $0.5 \%$ heavy bupivacaine. Our aim was to assess the onset and duration of sensory and motor blockade following IV dexmedetomidine supplementation after SAB.

Materials and Methods: Sixty American Society of Anesthesiologists Grade I and II patients undergoing elective surgeries under spinal anesthesia were randomized into two groups of 30 each. Immediately after subarachnoid block with $3 \mathrm{ml}$ of $0.5 \%$ hyperbaric bupivacaine, patients in group II received a loading dose of $1 \mu \mathrm{g} / \mathrm{kg}$ of dexmedetomidine intravenously by infusion pump over $10 \mathrm{~min}$ followed by a maintenance dose of $0.5 \mu \mathrm{g} / \mathrm{kg} / \mathrm{hr}$ till the end of surgery, whereas patients in group I received an equivalent quantity of normal saline. The time to reach peak sensory block level, time taken for two segment regression and maximum motor block, total duration of sensory and motor blockade, Ramsay sedation score and modified Bromage score were statistically analyzed using Statistical Package for Social Sciences (SPSS Inc. Chicago, IL, USA) Windows-based version 16.0.

Results: Two segment regression time of sensory blockade was more in the dexmedetomidine group (130.33 \pm 14.49 mins) as compared to the normal saline group $(94.67 \pm 15.02$ mins $)$ which was statistically significant $(\mathrm{P}<0.0001)$. The duration of both sensory ( $277.67 \pm 24.73$ mins vs. $173.67 \pm 12.45$ mins $)$ and motor blockade (206 \pm 23.72 mins vs. $135 \pm 13.83$ mins $)$ was more in the dexmedetomidine group than the normal saline group $(\mathrm{P}<0.0001)$.

Conclusion: The results of the present study shows that, intravenous dexmedetomidine given as a loading dose followed by maintenance dose prolonged the duration of sensory and motor blockade of bupivacaine-induced spinal anesthesia. It also provided conscious sedation without respiratory depression while maintaining good hemodynamic stability.
\end{abstract}

Keywords: Intravenous dexmedetomidine, Spinal anesthesia, $0.5 \%$ bupivacaine.

\section{Introduction}

Spinal anesthesia is a commonly used technique in anesthetic practice for gynecological, lower abdominal, pelvic, and lower limb surgeries. Different adjuvants have been used to prolong spinal anesthesia, with the probable benefits of late commencement of postoperative pain and reduced analgesic requirements. ${ }^{1}$ Adjuvants like alpha-2 adrenoceptor agonists like dexmedetomidine and clonidine have been recently used for their sedative, analgesic, and perioperative sympatholytic and cardiovascular stabilizing effects with reduced anesthetic requirements. ${ }^{2}$

Dexmedetomidine is a highly selective alpha-2 adrenergic agonist with an affinity eight times greater than that of clonidine. ${ }^{3}$ Systemic and intrathecal injection of dexmedetomidine produces analgesia by acting at spinal level, laminae VII and VIII of the ventral horns of the spinal cord. ${ }^{4}$ Intravenous dexmedetomidine can be titrated to the desired level of sedation with decreased inhalational anesthesia and opioid requirements during general anesthesia. ${ }^{5}$ Dexmedetomidine as a neuraxial adjuvant when given intrathecally with hyperbaric bupivacaine provides stable hemodynamic conditions, good quality of intraoperative and prolonged postoperative analgesia with minimal side effects. ${ }^{6-8}$ When intravenous dexmedetomidine is used in conjunction with neuraxial anesthesia, few studies have shown that it prolongs the sensory-motor blockade and provides better intraoperative and postoperative analgesia. ${ }^{9-16}$ Most studies have used $1 \mathrm{mcg} / \mathrm{kg}$ bolus followed by continuous intravenous infusion of $0.5 \mu \mathrm{g} / \mathrm{kg} / \mathrm{hr} .{ }^{17,18}$

Based on previous studies, ${ }^{9-16}$ we formulated our hypothesis that intravenous dexmedetomidine bolus followed by infusion would prolong the duration of subarachnoid block with $0.5 \%$ heavy bupivacaine. Our aim was to assess the onset and duration of sensory and motor blockade following IV dexmedetomidine supplementation during SAB. We also evaluated the effect of IV dexmedetomidine supplementation on haemodynamic parameters, sedation and adverse effects if any. 


\section{Materials and Methods}

After approval from the hospital ethics committee, this randomized double blind prospective study was carried out on 60 patients, aged 18 to 60 years of both sexes of American Society of Anesthesiologists Grades I and II, undergoing elective lower abdominal and lower limb surgeries less than 3 hours duration under subarachnoid block. Exclusion criteria included patient refusal, contraindications to spinal anesthesia, morbidly obesity, less than $150 \mathrm{cms}$ in height, significant respiratory, hepatic or renal diseases, pregnant and lactating women and patients having known allergy to the study drugs or their constituents.

All the patients fulfilling selection criteria were explained about the nature of the study and intervention and written informed consent was obtained from all the patients before enrollment. A total of sixty (60) patients were divided into two groups namely Group I and Group II by using computerized randomization. Patients were divided into two similar groups (30 subjects each) and assigned to receive either dexmedetomidine (Group II) or normal saline (Group I) intravenously. All patients were kept nil by mouth from midnight before surgery and tablet alprazolam $(0.01$ $\mathrm{mg} / \mathrm{kg}$ ) was administered at bedtime the day before surgery. In the operation theatre, all patients were connected to electrocardiography, peripheral oxygen saturation $(\mathrm{SpO} 2)$ and non invasive blood pressure monitor and all the basal parameters were recorded. An IV line was obtained with 18 gauge cannula and all patients were preloaded with Ringer's lactate solution $10 \mathrm{ml} / \mathrm{kg}$ body weight.

Under strict aseptic conditions, subarachnoid block was performed at L3-L4 intervertebral space through midline approach using a 25-gauge Quincke spinal needle. After ensuring free flow of cerebrospinal fluid, $0.5 \%$ heavy bupivacaine $15 \mathrm{mg}(3 \mathrm{ml})$ was administered intrathecally. Immediately after subarachnoid block, group II patients received a loading dose of $1 \mu \mathrm{g} / \mathrm{kg}$ of dexmedetomidine diluted to $50 \mathrm{ml}$ normal saline intravenously by infusion pump over 10 minutes followed by a maintenance dose of 0.5 $\mu \mathrm{g} / \mathrm{kg} / \mathrm{hr}$ till the end of surgery, whereas group I received an equivalent quantity of normal saline as loading and maintenance dose intravenously by infusion pump and served as control. The study drug was injected by an independent anesthesiologist in a double blind fashion who did not participate in observation or collection of data. Both the patient and the anesthesiologist were blinded to the treatment group, and all recordings were performed by an anesthesiologist, who was blinded to the randomization schedule.

Sensory block was assessed by pinprick using a small needle at mid axillary line every minute until it reached its maximum level. When the sensory block reached T6, surgery was allowed to proceed. Onset of sensory block was considered when the level of blockade reached $\mathrm{T} 8$. Time taken for the highest level of sensory blockade, two dermatomal regression from the maximum level and regression to S1 level was also noted. Sensory blockade was assessed at every 2 minute for the first 10 minutes and thereafter every 10 minutes during surgery and postoperatively.

The motor block of both legs was assessed using the Modified Bromage scale ${ }^{19}(0=$ full movement, $1=$ unable to raised extended leg, $2=$ unable to flex knee, 3 $=$ no movement $)$ and assessment was continued till normal motor function returned. Onset of motor block was considered when Bromage grade 3 was reached. The duration of motor block was taken as the time from full intensity motor blockade until a Bromage grade 0 score was achieved. Time taken for motor blockade to reach Modified Bromage Scale 3 and regression of motor blockade to Modified Bromage Scale 0 was noted. Motor blockade was assessed every 2 minutes before the onset of the surgery and every 10 minutes in post anaesthesia care unit (PACU).

The changes in heart rate, systolic and diastolic blood pressure were recorded at 0, 4, 6,10, 20 mins and 30 minutes and then at 30-min intervals up to $300 \mathrm{~min}$ after $\mathrm{SAB}$, or up to the end point of study. The level of sedation was evaluated both intra operatively and post operatively every 15 minute using Ramsay Sedation Scale $^{20}$ (Table 1) till the patient was discharged from PACU. Excessive sedation was defined as score greater than 4/6.The level of sedation was evaluated intraoperatively and post-operatively every $15 \mathrm{~min}$.

Table 1: Ramsay sedation score $(1-6)$

\begin{tabular}{|l|l|}
\hline Grade & Criteria \\
\hline I & Patient anxious, agitated, or restless \\
\hline II & $\begin{array}{l}\text { Patient cooperative, oriented, and } \\
\text { tranquil alert }\end{array}$ \\
\hline III & Patient responds to commands \\
\hline IV & $\begin{array}{l}\text { Asleep, but with brisk response to light } \\
\text { glabellar tap or loud auditory stimulus }\end{array}$ \\
\hline V & $\begin{array}{l}\text { Asleep, sluggish response to light } \\
\text { glabellar tap or loud auditory stimulus }\end{array}$ \\
\hline VI & Asleep, no response \\
\hline
\end{tabular}

Postoperatively, pain was assessed using visual analogue scale (VAS). The duration of analgesia was calculated as the time to reach a VAS score of $\geq 3$. Injection diclofenac $75 \mathrm{mg}$ intramuscular was used as rescue analgesic. Complications such as hypotension, bradycardia, nausea, vomiting, shivering, urinary retention and headache were also noted. Hypotension was defined as a decrease in MAP $<65 \mathrm{~mm}$ of $\mathrm{Hg}$ and treated with IV bolus of $6 \mathrm{mg}$ injection ephedrine and $100 \mathrm{ml}$ of Ringer lactate. Bradycardia was defined as HR $<60$ beats/min and treated with injection atropine $0.6 \mathrm{mg}$ IV bolus.

Sample Size: Based on a previous study, ${ }^{21}$ we calculated that a minimum of 30 patients were needed in each group to demonstrate a $15 \%$ difference in the 
duration of postoperative analgesia with an $\alpha$-error of 0.05 and a power of $80 \%$.

\section{Statistical Analysis}

Data were analyzed using computer statistical software system SPSS $®$ version 16 (Statistical Packages for the Social Sciences, Chicago, IL). The parameters recorded were compared between the two groups using chi-square test and independent Student's t-test. $\mathrm{P}$ value $<0.05$ was considered as statistically significant.

\section{Results}

All patients in both the study groups were similar with respect to sex, age, body weight, height and ASA status $(\mathrm{P}>0.05)$ [Table 2]. There was no difference in the onset of sensory block amongst the groups (6.67 \pm 1.84 mins in Group I vs 6.27 \pm 1.95 mins in Group II). The time taken to achieve the highest level of sensory block was $25.47 \pm 13.82$ and $27.47 \pm 12.54$ minutes in Group I (Normal saline) and Group II (Dexmedetomidine) respectively $(\mathrm{P}>0.05)$. The highest level of sensory block in group II was T4 (14 minutes) and T6 level in group I (12 minutes).

Two segment regression time of sensory blockade was more in the dexmedetomidine group $(130.33 \pm 14.49$ mins) as compared to the normal saline group (94.67 \pm 15.02 mins) which was statistically significant $(\mathrm{P}<0.0001)$. However the duration of effective sensory analgesia was more in the dexmedetomidine group $(277.67 \pm 24.73$ mins) than the normal saline group (173.67 \pm 12.45 mins) $(\mathrm{P}<0.0001)$ [Table 3].

The onset of motor block was $8.87 \pm 1.36$ and $8.53 \pm 1.38$ minutes in Group I and Group II respectively $(\mathrm{P}>0.05)$. Duration of motor blockade (206 \pm 23.72 mins vs. $135 \pm 13.83$ mins) was more in the dexmedetomidine group than the normal saline group ( $\mathrm{P}<0.0001)$ [Table 3]. The mean time for the duration of surgery in group I was 80.2 minutes and in group II 81.2 minutes were found to be statistically insignificant $(\mathrm{P}$ value $>0.05)$ [Table 3].

The patients in both the groups were comparable in terms of baseline heart rate, systolic and diastolic blood pressure and mean arterial pressure $(\mathrm{P}>0.05)$ [Table 4]. The mean heart rate at $12,14,16,18$ and 20 minutes in group I $(69.33 \pm 11.96,67.23 \pm 7.35,69.27 \pm 11.96$, $66.77 \pm 10.15$ and $66.63 \pm 9.19)$ was significantly higher $(\mathrm{P}<0.05)$ than group II $(64.4 \pm 5.40,63.9 \pm 5.16$, $64.4 \pm 5.04,62.4 \pm 4.90$ and $62.83 \pm 6.03)$. The heart rate in both the groups reached the lowest value at approximately the same time that is around 18 minutes and 20 minutes in group I $(66.77 \pm 10.15,66.63 \pm 9.19)$ while in group II $(62.4 \pm 4.90,62.83 \pm 6.03)$ and were statistically significant $(\mathrm{P}<0.05)$. In both the groups the heart rates came around baseline values at 120 minutes. In group I it was $77.77 \pm 6.23 \mathrm{bpm}$ and in group II it was $75.53 \pm 6.07 \mathrm{bpm}$ which were statistically insignificant $(\mathrm{p}>0.05)$ [Table 5].

The baseline mean arterial pressure in group I was 93.31 $\pm 4.96 \mathrm{~mm}$ of $\mathrm{Hg}$ and in group II was 91.60 \pm 5.07 $\mathrm{mm}$ of $\mathrm{Hg}$ which were statistically insignificant $(\mathrm{P}>0.05)$. The MAP in both groups was found to be comparable throughout the study period $(\mathrm{P}>0.05)$. The Mean arterial pressure in both the groups reached the lowest value at approximately the same time that is around 14 minutes and 16 minutes and were comparable $(\mathrm{P}>0.05)$.In both the groups the Mean arterial pressure came around baseline values at 120 minutes. In group I it was $91.19 \pm 3.87 \mathrm{~mm} \mathrm{Hg}$ and in group II it was $91.04 \pm 4.45 \mathrm{~mm} \mathrm{Hg}$ which were statistically insignificant $(\mathrm{P}>0.05)$ [Table 6].

Intraoperative Ramsay sedation scores were significantly higher in group II (Mean 3.40 \pm 0.80 , Range 2.1-4.2) as compared to group I (Mean $2.08 \pm 0.03$, Range 2-2.1) $(\mathrm{P}<0.0001)$. Maximum scores in group II ranged from 4-5 with a mean of 4.43. In group II maximum sedation score more than 4 was achieved in $43 \%$ of patients (13/30). Maximum scores in group I ranged from 2-3 with a mean of 2.77 [Table 7]. 5 patients in group I and 8 patients in group II develop hypotension requiring treatment which was statistically non significant. Nausea occurred in 2 patients in group I and 3 patients in group II which was also not significant. No patient in any group had bradycardia, vomiting, urinary retention, headache or pruritus. Post-operatively there was no significant difference between the two groups with respect to mean pulse rate, systolic and diastolic blood pressure, respiratory rate and mean arterial pressure.

Table 2: Demographic data of patients under study

\begin{tabular}{|l|c|c|c|}
\hline \multicolumn{1}{|c|}{ Characteristics } & Group I & Group II & P value \\
\hline Sex(Males/ Females) & $7 / 23$ & $8 / 22$ & $>0.05$ \\
\hline Mean age (yrs) & $38.2 \pm 8.87$ & $39.37 \pm 8.52$ & $>0.05$ \\
\hline Mean body weight (kg) & $57.9 \pm 8.01$ & $57.83 \pm 7.87$ & $>0.05$ \\
\hline ASA Grade (I/II) & $26 / 4$ & $24 / 6$ & $>0.05$ \\
\hline Height & $162.1 \pm 6.14 \mathrm{~cm}$ & $161.97 \pm 5.34 \mathrm{~cm}$ & $>0.05$ \\
\hline
\end{tabular}


Table 3: Sensory block, motor block and analgesia in Groups I and II (Mean \pm SD)

\begin{tabular}{|l|c|c|c|}
\hline \multicolumn{1}{|c|}{ Parameter } & Group I (n -30) & Group II (n-30) & P - Value \\
\hline Onset of sensory block (mins) & $6.67 \pm 1.84$ & $6.27 \pm 1.95$ & $\mathrm{NS}(>0.05)$ \\
\hline $\begin{array}{l}\text { Two segment regression time of sensory } \\
\text { blockade (mins) }\end{array}$ & $94.67 \pm 15.02$ & $130.33 \pm 14.49$ & $\mathrm{~S}(<0.0001)$ \\
\hline Time to achieve highest level of Block (mins) & $25.47 \pm 13.82$ & $27.47 \pm 12.54$ & $\mathrm{NS}(>0.05)$ \\
\hline Onset time complete motor blockade (mins) & $8.87 \pm 1.36$ & $8.53 \pm 1.38$ & $\mathrm{NS}(>0.05)$ \\
\hline Duration of motor blockade (mins) & $135 \pm 13.83$ & $206 \pm 23.72$ & $\mathrm{~S}(<0.0001)$ \\
\hline Duration of effective analgesia (mins) & $173.67 \pm 12.45$ & $277.67 \pm 24.73$ & $\mathrm{~S}(<0.0001)$ \\
\hline Duration of Surgery (mins) & $80.2 \pm 17.68$ & $81.2 \pm 18.15$ & $\mathrm{NS}(>0.05)$ \\
\hline
\end{tabular}

$\mathrm{SD}=$ Standard deviation $\mathrm{NS}=$ Not significant $(\mathrm{P}$ value $>0.05) \mathrm{S}=$ Significant $(\mathrm{P}<0.05) \mathrm{n}=$ number of patients

Table 4: Baseline hemodynamic parameters (Mean \pm SD)

\begin{tabular}{|l|c|c|c|}
\hline \multicolumn{1}{|c|}{ Parameters } & Group I & Group II & P value \\
\hline HR(bpm) & $81.4 \pm 8.13$ & $80.00 \pm 8.49$ & $>0.05$ \\
\hline SBP $(\mathrm{mmHg})$ & $124.60 \pm 6.15$ & $122.47 \pm 6.40$ & $>0.05$ \\
\hline DBP $(\mathrm{mmHg})$ & $77.67 \pm 5.31$ & $76.33 \pm 5.66$ & $>0.05$ \\
\hline MAP $(\mathrm{mmHg})$ & $93.31 \pm 4.96$ & $91.60 \pm 5.07$ & $>0.05$ \\
\hline
\end{tabular}

Table 5: Hemodynamic parameters - Heart rate (Mean \pm SD)

\begin{tabular}{|l|c|c|c|c|c|}
\hline \multirow{2}{*}{$\begin{array}{c}\text { Time interval } \\
\text { (minutes) }\end{array}$} & \multicolumn{2}{|c|}{ Group I } & \multicolumn{2}{c|}{ Group II } & \multirow{2}{*}{ P Value } \\
\cline { 2 - 5 } & Mean & SD & Mean & SD & P \\
\hline 0 & 81.4 & 8.13 & 80 & 8.49 & $>0.05$ \\
\hline 4 & 72.53 & 7.39 & 70.3 & 6.64 & $>0.05$ \\
\hline 6 & 72.1 & 8.39 & 69.57 & 7.74 & $>0.05$ \\
\hline 10 & 68.67 & 6.72 & 66.37 & 7.16 & $>0.05$ \\
\hline 20 & 66.63 & 9.19 & 62.83 & 6.03 & $<0.05$ \\
\hline 30 & 67.87 & 7.10 & 65.33 & 7.36 & $>0.05$ \\
\hline 60 & 72.53 & 8.43 & 69.73 & 6.72 & $>0.05$ \\
\hline 90 & 75.83 & 7.42 & 73.5 & 6.89 & $>0.05$ \\
\hline 120 & 77.77 & 6.23 & 75.53 & 6.07 & $>0.05$ \\
\hline
\end{tabular}

Graph 1: Inter group comparison of Mean Heart rates (bpm) at different times

\section{Haeodynamic Parameters - Heart Rate}

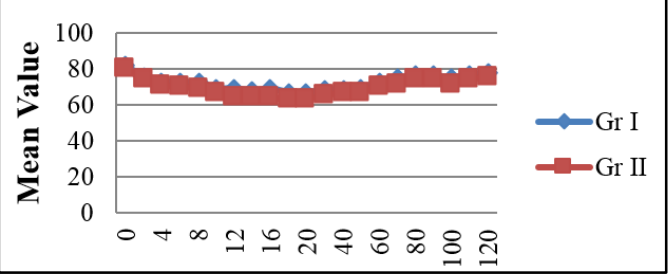

Table 6: Hemodynamic parameters - Mean arterial pressure (Mean \pm SD)

\begin{tabular}{|l|c|c|c|c|c|}
\hline \multirow{2}{*}{$\begin{array}{c}\text { Time interval } \\
\text { Minutes) }\end{array}$} & \multicolumn{2}{|c|}{ Group I } & \multicolumn{2}{c|}{ Group II } & \multirow{2}{*}{ P Value } \\
\cline { 2 - 5 } & Mean & SD & Mean & SD & \\
\hline 0 & 93.31 & 4.96 & 91.60 & 5.07 & $>0.05$ \\
\hline 4 & 85.67 & 4.54 & 84.02 & 3.88 & $>0.05$ \\
\hline 6 & 83.83 & 5.34 & 81.89 & 3.49 & $>0.05$ \\
\hline 10 & 76.91 & 2.98 & 77.91 & 2.85 & $>0.05$ \\
\hline 20 & 80.16 & 3.44 & 79.22 & 4.94 & $>0.05$ \\
\hline 30 & 82.89 & 4.99 & 82.27 & 4.40 & $>0.05$ \\
\hline 60 & 88.65 & 4.61 & 86.42 & 5.15 & $>0.05$ \\
\hline 90 & 90.36 & 4.23 & 89.93 & 5.71 & $>0.05$ \\
\hline 120 & 91.19 & 3.87 & 91.04 & 4.45 & $>0.05$ \\
\hline
\end{tabular}


Graph 2: Inter group comparison of Mean Arterial Pressure (mmHg) at different times

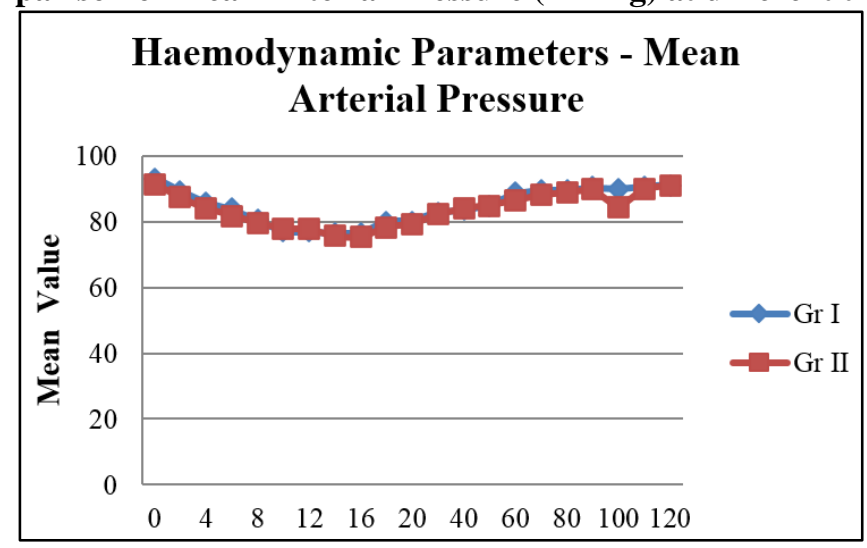

Table 7: Ramsay Sedation Score $(1-6)($ Mean \pm SD)

\begin{tabular}{|l|c|c|c|c|c|}
\hline \multirow{2}{*}{$\begin{array}{c}\text { Time interval } \\
\text { (Minutes) }\end{array}$} & \multicolumn{2}{|c|}{ Group I } & \multicolumn{2}{c|}{ Group II } & \multirow{2}{*}{ P Value } \\
\cline { 2 - 5 } & Mean & SD & Mean & SD & P Valu \\
\hline 0 & 2 & & 2.03 & 0.18 & \\
\hline 15 & 2.1 & 0.30 & 2.4 & 0.49 & $<0.0001$ \\
\hline 30 & 2.1 & 0.30 & 3.37 & 0.49 & $<0.0001$ \\
\hline 60 & 2.1 & 0.30 & 3.9 & 0.35 & $<0.0001$ \\
\hline 90 & 2.1 & 0.30 & 4.07 & 0.25 & $<0.0001$ \\
\hline 120 & 2.07 & 0.25 & 4.2 & 0.41 & $<0.0001$ \\
\hline 180 & 2.07 & 0.25 & 4.07 & 0.25 & $<0.0001$ \\
\hline 240 & 2.03 & 0.18 & 2.2 & 0.41 & $<0.0001$ \\
\hline
\end{tabular}

Graph 3: Inter group comparison of the baseline, intraoperative and postoperative (PO) Ramsay sedation scores

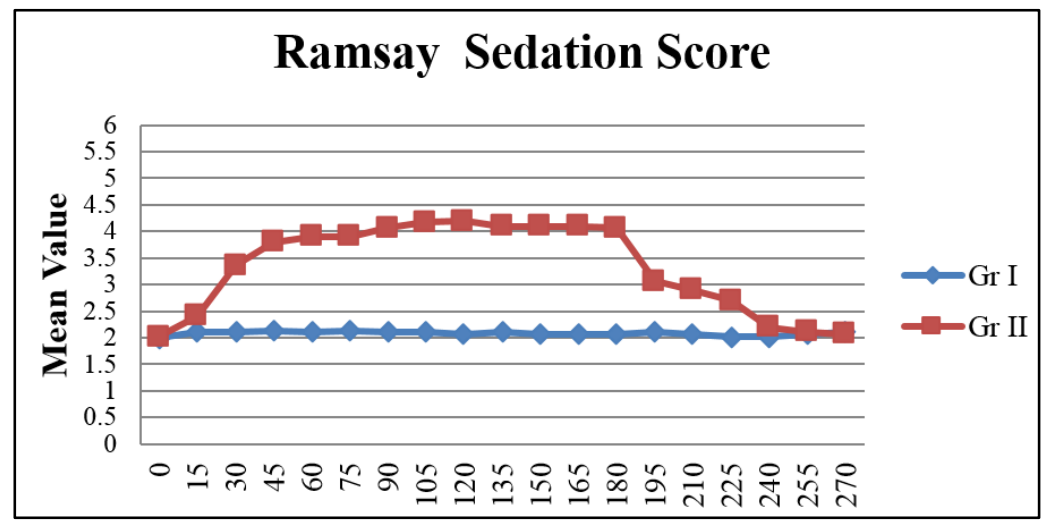

\section{Discussion}

Dexmedetomidine is a $\alpha 2$ agonist which was approved by the Food and Drug Administration (FDA) in 1999 for use as an analgesic and sedative in the intensive care units. ${ }^{22}$ Different $\alpha$-adrenoceptor agonists have different $\alpha 1: \alpha 2$ selectivity. Alpha 2 agonist inhibits adenyl cyclase activity, reduces brainstem vasomotor center-mediated CNS activation producing sympatholysis, anxiolysis, sedation and possess some analgesic properties. ${ }^{23}$ Dexmedetomidine differs from clonidine as it has 8 times more affinity for $\alpha 2$ receptors than that of clonidine. It also possesses most selective $\alpha 2$ adrenoceptor agonist activity especially for the $2 \mathrm{~A}$ subtype of this receptor, which makes it a more potent sedative and analgesic agent than clonidine. ${ }^{24}$ The exact mechanism by which dexmedetomidine prolongs local anesthetic effect is not clear. However, dexmedetomidine acts by binding to presynaptic C fibers and postsynaptic dorsal horn neurons, thus depressing the release of $\mathrm{C}$ fiber transmitters and hyperpolarizing dorsal horn postsynaptic neurons. This may cause an additive synergistic effect to the mechanism of action of local anesthetics. ${ }^{25}$ In case of intravenous dexmedetomidine administration, although the mechanism remains unclear, the supraspinal direct 
analgesic and the vasoconstrictive effect of dexmedetomidine are likely to be involved. ${ }^{26-28}$

Our study revealed that intravenous dexmedetomidine increased both the duration of sensory and motor block which was statistically significant. In our study, the median value for the highest level of sensory block in group II was T4 (14 minutes) and T6 level in group I (12 minutes). Sensory block level achieved was higher $(\mathrm{p}<0.001)$ in group II than in group I in our study. Our findings are similar to the findings by Victor Whizar-Lugo et al (2007), ${ }^{22}$ Kaya et al (2010) ${ }^{1}$, Reddy et al $(2013)^{29}$, Harsoor et al (2013). ${ }^{14}$ In our study, mean time for two dermatomal regression of sensory blockade was significantly prolonged in group II [130.33 \pm 14.49 minutes] compared to group I [ $94.67 \pm 15.02$ minutes] which was statistically significant. Significant prolongation in mean time for two dermatomal regression of sensory blockade was also reported by others [Kaya et al ${ }^{1}-145$ \pm 26 min vs. $97.1 \pm 26.5$ mins $(\mathrm{P}<0.001)$, Tekin et $\mathrm{al}^{10}-148.3$ mins vs. 122.8 mins ( $\mathrm{P}$ value $\left.<0.001\right)$ in dexmedetomidine and control groups respectively]. Similar findings were also reported by Hong et al, ${ }^{30}$ Elcicek et $\mathrm{al}^{13}$ and Reddy et al. ${ }^{29}$

The duration of sensory blockade i.e. time for regression to $\mathrm{S} 1$ dermatome was significantly prolonged in group II [277.67 $\pm 24.73 \mathrm{~min}]$ compared to group I [173.67 $\pm 12.45 \mathrm{~min}](\mathrm{P}$ value $<0.0001)$ in our study. Significant prolongation in mean duration of sensory blockade in dexmedetomidine group was also reported by others [Al Mustafa et $\mathrm{al}^{26}(261.5 \pm 34.8 \mathrm{~min}$ vs. $165.2 \pm 31.5 \mathrm{~min}$ ), Victor Whizar-Lugo et $\mathrm{al}^{22}$ [208 \pm 43.5 mins vs. $137 \pm 121.9$ mins $(\mathrm{P}=0.05)$, Abdelkarim S, ${ }^{31} 209.6 \pm 25.9$ min vs. $149.4 \pm 14.6$ min (P value $<0.0001)$ in dexmedetomidine and control groups respectively].

In the present study there was no significant difference in time taken for motor blockade to reach modified Bromage Scale 3 in both the groups [ $8.53 \pm 1.38 \mathrm{~min}$ in group II compared to $8.87 \pm 1.36 \mathrm{~min}$ in group I, P value >0.05]. However, the regression time to reach the modified Bromage Scale 0 scale was significantly prolonged in group II [206 $\pm 23.72 \mathrm{mins}]$ compared to group I [135 \pm 13.83 mins] ( $\mathrm{P}$ value < 0.0001). Delay in motor block regression to Bromage Scale 0 was also reported in previous studies [Al Mustafa et $\mathrm{al}^{26}(199.9 \pm 42.8 \mathrm{~min}$ in vs138.4.

$\pm 31.3 \mathrm{~min})(\mathrm{P}$ value $<0.0001)$, Victor WhizarLugo et al, ${ }^{22}(191 \pm 49.8$ mins vs. $172 \pm 36.4)$ (P valuenot significant), Tekin et al ${ }^{10} 215$ mins vs. 190.8 mins (Pvalue < 0.001) for dexmedetomidine group and control group respectively]. Abdelkarim $\mathrm{S}^{31}$ also observed that the regression time to reach the Bromage 0 scale was $255.8 \pm 36.7 \mathrm{~min}$ in Dexmedetomidine group which was higher than the control group $(184.6 \pm 22.8$ min) ( $\mathrm{P}<0.0001)$. Elcicek et $\mathrm{al}^{13}$ and Hong et $\mathrm{al}^{30}$ and Harsoor et $\mathrm{al}^{14}$ also found that complete resolution of motor blockade was significantly prolonged in dexmedetomidine group. But contrary to all the above studies, Kaya et al ${ }^{1}$ reported no significant prolongation in the duration of motor block in dexmedetomidine group compared to control group [193 $\pm 27 \mathrm{~min}$ in Dexmedetomidine group vs. $180 \pm 34$ in control group]. Also Reddyet $\mathrm{al}^{29}$ found no difference in duration of motor block between the Dexmedetomidine group and control group.

In our study intraoperative Ramsay sedation scores were significantly higher in the Dexmedetomidine group. Maximum sedation score in Dexmedetomidine group more than 4 was achieved in $43 \%$ of patients (13/30). Ramsay sedation score ranged from $2-5$ in dexmedetomidine group in the study done by Mahmoud $\mathrm{M}$ Al-Mustafa et al. ${ }^{26}$ Hong et $\mathrm{al}^{28}$ noted that the median sedation scores during surgery were 4 in the dexmedetomidine group and 2 in the control group. The hypnotic and supraspinal analgesic effects of Dexmedetomidine are mediated by the hyperpolarization of noradrenergic neurons, which suppresses neuronal firing in the locus ceruleus along with inhibition of norepinephrine release and activity in the descending medullospinal noradrenergic pathway, secondary to activation of central $\alpha 2$-ARs. ${ }^{32}$ This suppression of inhibitory control triggers neurotransmitters that decrease histamine secretion producing hypnosis similar to normal sleep, without ventilatory depression, making Dexmedetomidine a near ideal sedative. ${ }^{33}$ Suppression of activity in the descending noradrenergic pathway, which modulates nociceptive neurotransmission, terminates propagation of pain signals leading to analgesia. ${ }^{34}$

Intraoperative and postoperative systolic, diastolic, and mean arterial blood pressures were comparable in the dexmedetomidine group and the control group in the present study. These findings concur with the findings of Al Mustafa et al. ${ }^{26}$ and Tekin et al. ${ }^{10}$ In our study, there was no significant difference in the number of patients requiring mephentermine for the management of hypotension in both the groups similar to the findings of Tekin et al., ${ }^{10} \mathrm{Al}$ Mustafa et al. ${ }^{26}$ and Lugo et al. ${ }^{22}$ There was also not much difference in the intraoperative respiratory rates between the groups similar to the published results of Mustafa et al. ${ }^{26}$

\section{Conclusion}

The results of the present study shows that, intravenous Dexmedetomidine given as a loading dose followed by maintenance dose prolonged the duration of sensory and motor blockade of bupivacaine-induced spinal anesthesia. It also provided good intraoperative conscious sedation without respiratory depression while maintaining good hemodynamic stability. 


\section{References}

1. Kaya FN, Yavascaoglu B, Turker G, Yildirim A, Gurbet A, Mogol EB. Intravenous dexmedetomidine, but not midazolam, prolongs bupivacaine spinal anesthesia. Can J Anesth. 2010;57(1):39-4.

2. Celik M, Koltka N, Cevik B, Baba H. Intraoperative sedation during epidural anesthesia: dexmedetomidine vs midazolam. Internet J Anesthesiol. 2008;17:2

3. 3.Hanoura SE, Hassanin R, Singh R. Intraoperative conditions and quality of postoperative analgesia after adding dexmedetomidine to epidural bupivacaine and fentanyl in elective cesarean section using combined spinal-epidural anesthesia. Anesth Essays Research. 2013;7:168-172.

4. Abdelkarim SA, Mahmoud MM, Jihad MA, Diana FM, Mohammad QH, Subhi MA, et al. Intravenous dexmedetomidine or propofol adjuvant to spinal anesthesia in total knee replacement surgery. Jordanian Med J. 2011;45:174-83.

5. Hall JE, Uhrich TD, Barney JA, Arain SR, Ebert TJ. Sedative, amnestic, and analgesic properties of smalldose dexmedetomidine infusions. Anesth Analg. 2000; 90:699-705.

6. Al-Ghanem SM, Massad IM, Al-Mustafa MM, Al-Zaben KR, Qudaisat IY, Qatawneh AM, Abu-Ali HM. Effect of Adding Dexmedetomidine versus Fentanyl to Intrathecal Bupivacaine on Spinal Block Characteristics in Gynecological Procedures: A Double Blind Controlled Study. Am J Appl Sci. 2009;6:882-7.

7. Al-Mustafa MM, Abu-Halaweh SA, Aloweidi AS, Murshidi MM, Ammari BA, Awwad ZM, et al. Effect of dexmedetomidine added to spinal bupivacaine for urological procedure. Saudi Med J. 2009;30:365-70.

8. Kanazi GE, Aouad MT, Jabbour-Khoury SI, Al Jazzar MD, Alameddine MM, Al-Yaman R, et al. Effect of lowdose dexmedetomidine or clonidine on the characteristics of bupivacaine spinal block. Acta Anesthesiol Scand. 2006; 50:222-7.

9. Vanda G. Yazbek-Karam, Marie M. Aouad. Perioperative uses of dexmedetomidine. M.E.J. Anesth. 2006;18:10431058.

10. Tekin M, Kati I, Tomak Y, Kisli E. Effect of dexmedetomidine IV on the duration of spinal anesthesia with Prilocaine: a double- blind, prospective study in adult surgical patients. Current Therapeutic Research. 2007;68:313-324.

11. Victor Whizar-Lugo, Irma A. Gomez-Ramirez, Roberto Cisneros-Corral, Nora Martinez-Gallegos. Intravenous Dexmedetomidine vs. Intravenous Clonidine to prolong Bupivacaine Spinal Anesthesia. A Double Blind Study. Anestesia en Mexico. 2007;19(3):143-146.

12. Mahmoud M Al-Mustafa, Izadiad Z Badran, Hamdi MAbu Ali, Bassam AAl-Barazangi, Islam M Massad and Subhi M. Al-Ghanem. Intravenous dexmedetomidine prolongs bupivacine spinal analgesia. MEJ Anesth. 2009;20:225-231.

13. Elcicek K, Tekin M, Kati I. The effects of intravenous dexmedetomidine on spinal hyperbaric ropivacaine anesthesia. J Anesth. 2010;24:544-8.

14. Harsoor S, Rani DD, Yalamuru B, Sudheesh K, Nethra S. Effect of supplementation of low dose intravenous dexmedetomidine on characteristics of spinal anaesthesia with hyperbaric bupivacaine. Indian J Anaesth. 2013;57:265-269.

15. Lee MH, Ko JH, Kim EM, Cheung MH, Choi YR, Choi EM. The effects of intravenous dexmedetomidine on spinal anesthesia: comparision of different dose of dexmedetomidine. Korean J Anesthesiol. 2014;67:252257.

16. Gupta K, Tiwari V, Gupta PK, Pandey MN, Agarwal S, Arora A. Prolongation of subarachnoid block by intravenous dexmedetomidine for sub umbilical surgical procedures: A prospective control study. Anesth Essays Res. 2014;18: 8:175-178.

17. Lugo VW, Gomez IA, Cisneros-Corral R, Martinez-Gallegos N.Intravenous dexmedetomidine versus intravenous clonidine to prolong bupivacaine spinal anesthesia. A double blind study. Anestesia en Mexico. 2007;19:143-6.

18. Al-Mustafa MM, Badran IZ, Abu-Ali HM, Al-Barazangi BA, Massad IM, Al-Ghanem SM. Intravenous dexmedetomidine prolongs bupivacaine spinal analgesia. Middle East J Anesthesiol. 2009;20:225-31.

19. Bromage PR, Burfoot MF, Crowell DE, Pettigrew RT. Quality of epidural blockade. I. influence of physical factors. Br J Anaesth. 1964;36:342-52.

20. Ramsay MA, Savege TM, Simpson BR, Goodwin R. Controlled sedation with alphaxalone-alphadolone. $\mathrm{Br}$ Med J. 1974;2:656-9.

21. Hadil Magdy, Mai Mohsen, Mohamed Saleh. The effect of intrathecal compared with intravenous dexmedetomidine as an adjuvant to spinal bupivacaine anesthesia for cesarean section. Ain-Shams J Anesthesiol. 08:93-99.

22. Whizar LV, Gomez-Ramirez IA, Cisneros-Corral R, Martinez-Gallegos N. Intravenous dexmedetomidine vs. intravenous clonidine to prolong bupivacaine spinal anaesthesia. A double blind study. Anestesia en Mexico. 2007;19:143-6.

23. Bhana N, Goa KL, McClellan KJ. Dexmedetomidine. Drugs. 2000;59:263-268.

24. Grewal A. Dexmedetomidine: New avenues. $J$ Anaesthesiol Clin Pharmacol. 2011;27:297-302.

25. Eisenach JC, De Kock M, Klimscha W. alpha (2)adrenergic agonists for regional anesthesia. A clinical review of clonidine (1984-1995). Anesthesiology. 1996; 85:655-674.

26. Al-Mustafa MM, Badran IZ, Abu-Ali HM, Al-Barazangi BA, Massad IM, Al- Ghanem SM. Intravenous dexmedetomidine prolongs bupivacaine spinal analgesia. Middle East J Anaesthesiol. 20 09;20:225-231.

27. Kaya FN, Yavascaoglu B, Turker G, Yildirim A, Gurbet A, Mogol EB, Ozcan B. Intravenous dexmedetomidine, but not midazolam, prolongs bupivacaine spinal anesthesia. Can J Anaesth. 2010;57:39-45.

28. Hong JY, Kim WO, Yoon Y, Choi Y, Kim SH, Kil HK. Effects of intravenous dexmedetomidine on low-dose bupivacaine spinal anaesthesia in elderly patients. Acta Anaesthesiol Scand. 2012;56:382-387.

29. Reddy VS, Shaik NA, Donthu B, Sannala VK, Jangam V. Intravenous dexmedetomidine versus clonidine for prolongation of bupivacaine spinal anesthesia and analgesia: A randomized double-blind study. $J$ Anaesthesiol Clin Pharmacol. 2013;29:342-7.

30. Hong JY, Kim WO, Yoon Y, Choi Y, Kim SH, Kil HK. Effects of intravenous dexmedetomidine on low-dose bupivacaine spinal anaesthesia in elderly patients. Acta Anaesthesiol Scand. 2012;56:382-7.

31. Abdel karim S. Al Oweidi, Mahmoud M. Al-Mustafa, Jihad M. Al Ajlouni, Diana F. Mas'ad, Mohammad Q. Hamdan, Subhi M. Alghanem, Ibraheem Y. Qudaisat, Sami A. Abu Halaweh, Islam M. Massad. Intravenous Dexmedetomidine or Propofol Adjuvant to Spinal 
Anesthesia in Total Knee Replacement Surgery. $J$ Med J. 2011;45(2):174-183.

32. Guo TZ, Buttermann AE, Jiang JY, Maze M.

Dexmedetomidine injection into the locus ceruleus produces antinociception. Anesthesiology. 1996;84:87381.

33. Nelson LE, You T, Maze M, Franks NP. Evidence that the mechanism of hypnotic action in dexmedetomidine and muscimol-induced anesthesia converges on the endogenous sleep pathway. Anesthesiology. 2001;95:A1368.

34. Ustun Y, Gunduz M, Erdogan O, Benlidayi ME. Dexmedetomidine versus midazolam in outpatient third molar surgery. J Oral Maxillofac Surg. 2006;64:1353-8.

\author{
How to cite this article: Thakuria R. Borah TJ, \\ Sonowal J, Choudhury D. Effects of intravenous \\ dexmedetomidine on $0.5 \%$ hyperbaric \\ bupivacaine spinal anesthesia - a placebo \\ controlled randomized trial. Indian $\mathbf{J}$ Clin \\ Anaesth. 2018;5(3):423-430.
}

